\title{
Occupational therapy in early intervention: a family-centered approach.
}

\author{
Roseann C. Schaaf \\ Thomas Jefferson University \\ L L. Mulrooney
}

Follow this and additional works at: https://jdc.jefferson.edu/otfp

Part of the Occupational Therapy Commons

Let us know how access to this document benefits you

\section{Recommended Citation}

Schaaf, Roseann C. and Mulrooney, L L., "Occupational therapy in early intervention: a familycentered approach." (1989). Department of Occupational Therapy Faculty Papers. Paper 22. https://jdc.jefferson.edu/otfp/22

This Article is brought to you for free and open access by the Jefferson Digital Commons. The Jefferson Digital Commons is a service of Thomas Jefferson University's Center for Teaching and Learning (CTL). The Commons is a showcase for Jefferson books and journals, peer-reviewed scholarly publications, unique historical collections from the University archives, and teaching tools. The Jefferson Digital Commons allows researchers and interested readers anywhere in the world to learn about and keep up to date with Jefferson scholarship. This article has been accepted for inclusion in Department of Occupational Therapy Faculty Papers by an authorized administrator of the Jefferson Digital Commons. For more information, please contact: JeffersonDigitalCommons@jefferson.edu. 


\section{Occupational Therapy in Early Intervention: A Family-Centered Approach}

\author{
Roseann C. Schaaf, Lisa L. Mulrooney
} Key Words: developmental therapy $\bullet$ patient
education $\bullet$ play skills training

This article describes a framework for occupational therapy service provision in early intervention settings and presents pilot data aimed at examining the framework's effectiveness. The Family-Centered Framework for Early Intervention is a synthesis of concepts from the Model of Human Occupation (Kielhofner $\&$ Burke, 1980) and from the literature on play. It encompasses a systematic, bolistic approach that considers the child and the family within the context of their life environments. In this framework, play is used both as an evaluative tool and as an intervention modality that addresses the volition, babituation, and performance of the child and family as well as the strengths and weaknesses of the environment. Play is also used as a primary measure of competence and change. This framework may be useful in defining occupational ther. apy roles for the early intervention population.

Roseann C. Schaaf, MEd, OTR/L, is an instructor in the Department of Occupational Therapy, Thomas Jefferson University, Suite 820,130 South 9 th Street, Philadelphia, Pennsylvania 19107. She is also in private practice, specializing in pediatrics.

Lisa L. Mulrooney, OTR/L, is in private practice in Wilming ton, Delaware, through Occupational and Physical Therapy Services of Delaware.

This article was accepted for publication July 22, 1989.
$\mathrm{T}$ The Education of the Handicapped Act Amend ments of 1986 (Public Law 99-457) identify occupational therapy as a primary early intervention service for infants and young children and their families. Occupational therapists, therefore, can in crease their involvement with this population, and the demand for occupational therapy services in early intervention will likely increase. Therapists must be prepared to meet the potential service demands created by this legislation and to establish themselves as primary service providers to infants, young children, and their families.

Public Law 99-457 emphasizes parental primacy, which places the emphasis of intervention on the family and gives the parents or primary caregivers a major role in decisions regarding the welfare and development of their child. Thus, occupational therapists will need to shift their focus from providing child-centered services to engaging in a partnership with par ents. As a result, the role of occupational therapy in early intervention will need to be redefined, and models of service provision that focus on the family will need to be developed. These new models of service provision will require validation through effectiveness studies to solidify occupational therapy's role as an effective and important early intervention service.

This article describes a family-centered frame. work for the provision of occupational therapy in early intervention settings and presents data from a pilot study that examined the effectiveness of this framework.

The Family-Centered Framework for Early Inter vention is based on the Model of Human Occupation (Kielhofner \& Burke, 1980) and provides an organized structure in which the role of occupational ther apy in early intervention is defined. This framework places the child and the family within the context of their life environments-Both human and nonhuman environmental factors are considered as they influence the child's competence during play. The values, interests, habits, routines, and skills of the child and the family are considered in the evaluation and intervention process. Treatment is focused not only on intervention with the child, but also directly on environmental adaptations that will enhance the competence of the family and child.

\section{The Family-Centered Framework for Early Intervention}

\section{Theoretical Basis}

The Family-Centered Framework for Early Intervention is a synthesis of concepts from the Model of Human Occupation (Kielhofner \& Burke, 1980; Kielhofner, Burke, \& Igi, 1980) and from the develop. mental literature on play (Chance, 1979; D'Eugenio, 1986; Lindquist, Mack, \& Parham, 1982a, 1982b; 
Munoz, 1986; Reilly, 1974; Takata, 1969, 1974). The Model of Human Occupation provides therapists with a systematic approach to understanding and working with the values, needs, habits, and skills of the family and child within their many environments. An overview of the model is presented here as a basis for the Family-Centered Framework for Early Intervention. For further information, see Kielhofner (1985), Kielhofner and Burke (1980), and Lindquist et al. (1982a, 1982b). The Model of Human Occupation views the person as an open system that is influenced by and acts on its respective environments (see Figure 1). According to this model, the open system comprises three major subsystems: volition, habituation, and performance. Volition involves motivation, interests, values, and goals that influence the person's or family's behavior. For example, in examining motivation, the therapist considers what factors motivate a child to play outdoors rather than watch television and how the family's values about children and play influence the child's play choice. Habituation involves the person's organization of daily life habits and routines within life roles. For a child, these roles may include those of child, peer, sibling, and student. Performance involves the skills and abilities that are available to a person as he or she performs daily self-care, play, academic, and work tasks along with other activities.

As parts of a system, the subsystems of volition, habituation, and performance interact with, shape, and influence each other continuously. The performance subsystem's influence over the volition subsystem can be seen in a child's interest in and desire to play as related to his or her physical abilities. For example, a child with decreased muscle tone and de-

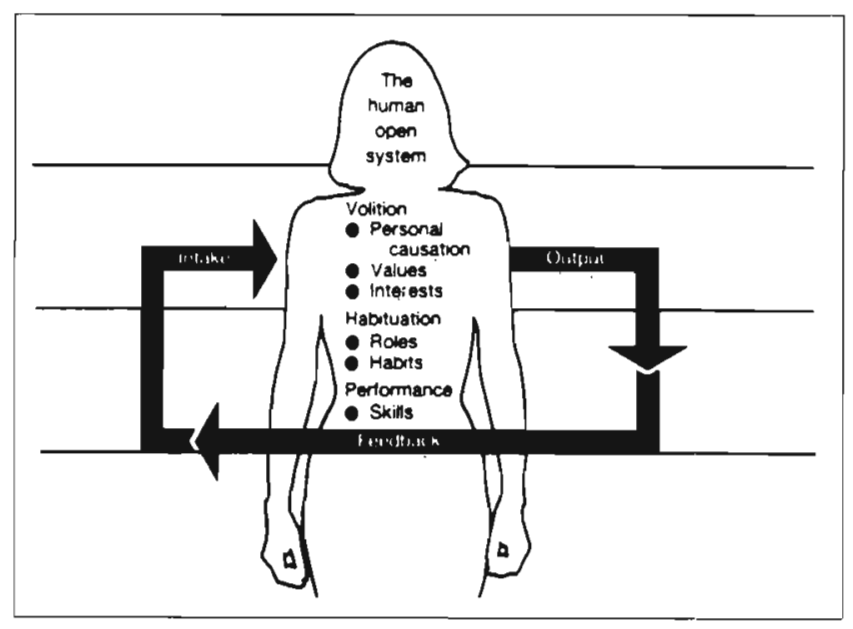

Figure 1. The human open system. From A Model of Human Occupation: Theory and Application (p. 13) by G. Kielhofner (Ed.), 1985, Baltimore: Williams \& Wilkins. Copyright 1985 by Williams \& Wilkins. Reprinted by permission. layed motor skills may choose a more sedentary activity such as watching television during free playtime because of a preference to do something for which he or she has the skill, whereas a well-coordinated child may choose to play on a riding toy outside. Conversely, the influence of the volition subsystem over the performance subsystem is illustrated by the way in which motivation and interest influence what a person chooses to do. For example, a child who is interested in imitating mommy may be motivated to move in new ways so that he or she can use a doll and carriage in play, or a child who is interested in playing with new friends down the street may be motivated to learn to ride a bike, although the family previously had been unable to facilitate an interest in bike riding The habituation subsystem's influence over the performance subsystem is seen in how the daily routines and habits of the family determine what the child has time to do. For example, in a family where both parents work, there may not be time for the child to develop the habits of self-dressing and eating in the morning. Thus, each of the subsystems influences the others as they interact.

According to the Model of Human Occupation, the environment affects all subsystems, because it enhances or limits the desire, the ability, or the organization of the system. A child's desire to play, for example, may be stifled in a home with limited or develop. mentally inappropriate toys. Both human (e.g., family, teachers, therapists, peers) and nonhuman (e.g., toys, play spaces) environmental factors need to be considered, because they significantly influence volition, habituation, and performance.

\section{Framework Design}

We have adapted the Model of Human Occupation to address early intervention. In our family-centered framework, play is seen as the primary occupational behavior of the child and the role of player as a primary role of childhood. Play is viewed as an arena for the practice of new skills and a method by which the child can obtain sensory input, enhance competence, and learn new skills (D'Eugenio, 1986; Florey, 1971). Play is an intrinsically enjoyable, self-motivating behavior that is not imposed or directed by adults (Chance, 1979). Within our framework, play is viewed as an activity that both reflects and facilitates the development of competence in interaction with the world (Ayres, 1972, 1979; Lindquist et al., 1982a, 1982b; Reilly, 1974; Takata, 1969). That is, play can give us clues about volition (the child's and family's values, needs, and interests), habituation (the child's and family's organization of behaviors into patterns and routines), performance (the child's skills and abilities), and environmental strengths and weak- 
nesses as well as help us to facilitate the child's development of skills, habits, roles, interests, and motiva tion (Kielhofner, 1985; Neville, Kielhofner, \& BrasicRoyeen, 1985)

The influences on a child's play as outlined by the Family-Centered Framework for Early Intervention are depicted in Figure 2. This conceptualization demonstrates how play serves as a window into the child's volition, habituation, and performance subsystems. By observing and analyzing a child's play, the therapist gains information about what the child chooses to do (volition), how much time the child has for play and how the child organizes play (habituation), what skills the child exhibits during playtime (performance), and the strengths and weaknesses of the human and nonhuman play environments. Play can also serve as a door through which the therapist can enter to design intervention strategies aimed at enhancing the quality of play. These strategies might include activities to strengthen a child's performance deficits through the pairing of play interests with skill deficits. For example, the child with a physical disability who lacks manipulative skills may be observed to prefer imaginary play, because that is the type of play that is most accessible and successful. Manipulative activities that incorporate the child's interest in imaginary play, such as a tea party for dolls where positioning; pouring; and controlled reach, grasp, and release are addressed, will be more enticing and suc-

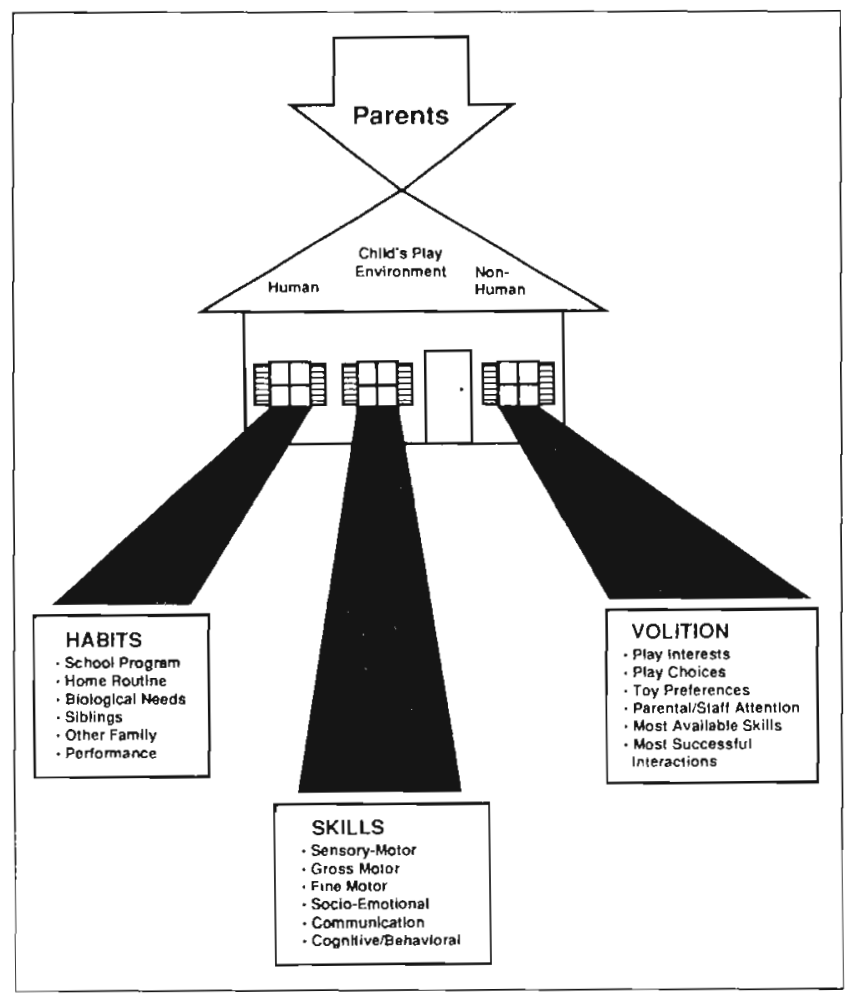

Figure 2. Influences on a child's play. cessful than activities that emphasize fine motor skills alone. This also illustrates how the framework allows the therapist to use information about the child's volition and habituation to enhance performance. The therapist can design other strategies to modify the environment or educate parents to be facilitators of play, thereby enhancing family competence.

The parents have a major effect on the play envi ronment and play behavior (see Figure 2); therefore, the therapist must consider the parents' values, interests, routines, goals, and skills when planning intervention strategies. The therapist must be able to analyze the family's occupational behavior, again con sidering the subsystems of volition, habituation, and performance, to formulate goals and treatment strategies that fit with the family's values, goals, habits, and skills.

Many of the other human and nonhuman environmental factors considered in the family-centered framework are listed below.

1. Human Environmental Factors

Parent-child interactions

Siblings

Peers

Teacher

Therapist

Early intervention program staff

2. Nonhuman Environmental Factors

Type of toy

Toy placement

Toy organization

Positioning of child

Play space

Play freedom

Home visits are an effective means by which to assess the environment and the family's occupational behavior. By observing the home environment and parent-child interactions and by asking questions about the parents' priorities for their child, the thera pist gains invaluable information for planning and designing a realistic intervention program. During home visits, the therapist can also gain insight into the parents' skill at providing toys appropriate to their child's developmental level, their ability to tap into their child's play interests and skills, their values in relation to play, and the family's habits and routines. Home visits also provide the therapist with an opportunity to directly observe the organization of the non. human play environment and its effect on the child's ability to engage in play activities. For example, a therapist working with a parent in the home environment may recognize that a child with an attention-deficit disorder needs toys organized on shelves up and out of reach so that one toy may be presented at a time to help focus the child's attention. Conversely, a child 
with a physical disability who is cognitively intact needs toys placed within easy reach so that he or she can reach them independently. Home visits also allow the therapist to gather information about daily routines (e.g, feeding, play, napping, and rising times) and demands placed on the parents. With this information, the therapist can develop suggestions that incorporate play activities, positioning, and self-help skills within existing routines and time limitations, thereby decreasing the chances of overwhelming or overburdening a parent who is often already stressed. The therapist can also use home visits as a time to formulate and implement intervention activities in conjunction with the parents. Home visits and other assessment and intervention strategies used in the application of the family-centered framework are presented in the following case example.

\section{Home Visit Analysis: A Case Example}

The home visit analysis demonstrates a breakdown of the subsystems of the child, parent, and environment within the family-centered framework and how this information influences intervention strategies (see Figure 3 ). In this case example, the child and mother had myotonic dystrophy, which caused them to have upper extremity weakness and limited energy. During home visits, the therapist (the second author) observed a limited repertoire of appropriate toys and

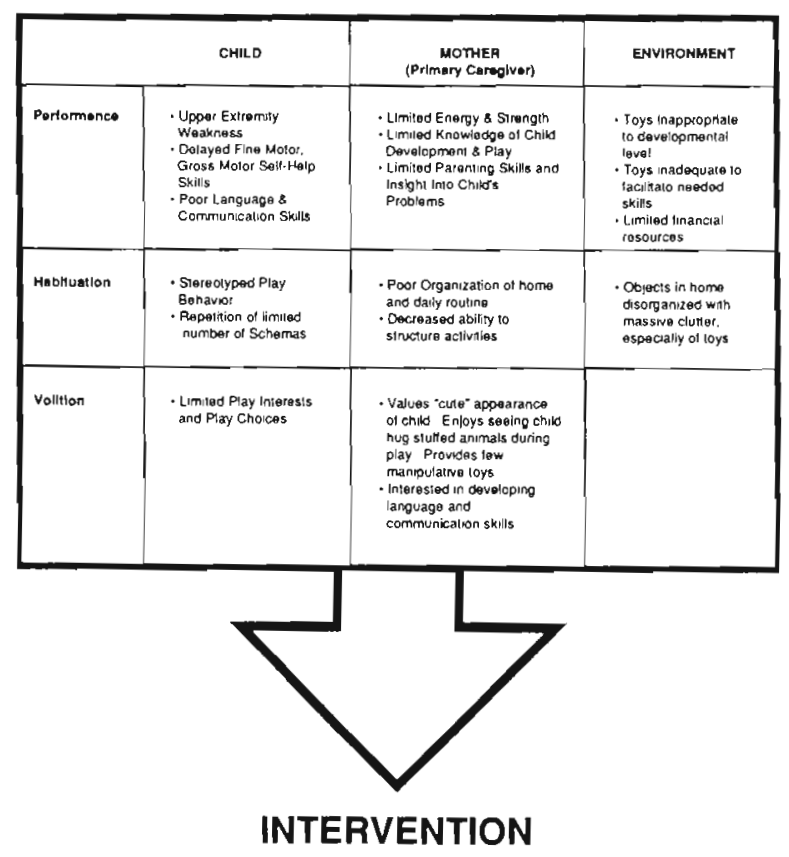

- Adapting the Play Environment

- Toy Library

- Parent Discussion Group

Figure 3. A home visit analysis play interests, a disorganized play environment, and limited parent-child play interactions. The mother valued language and communication skills as the most important area of development for her child. The child's strongest play interest was bringing books to her mother and then sitting in her mother's lap and looking at the pictures. By considering the parents' values and interests in conjunction with the child's interests, skills, and needs along with the strengths and weaknesses of the environment, the therapist formulated several intervention strategies.

Adaptation of the play environment. The environment was adapted in several ways to facilitate the child's competence and to encourage family interaction. For example, because the child showed an interest in books and the parent valued reading to the child, activities that involved manipulative books (i.e., books containing finger holes; flaps; and snaps, zippers, and buttons) were suggested. The suggestion that the child return the book to a special book basket when finished also encouraged the following of directions and environmental organization. The activity thus addressed communication skills, mobility, organization of the play environment, fine motor skills, and parent-child interaction. Because both the mother and the child valued the activity, it was used frequently by the family.

Toy library. A toy library is a resource that can enrich the home play environment. The therapist can use information gathered from assessment data to guide the borrowing of toys, thereby enriching the child's environment and encouraging competence through environmental adaptation. The toy library was quite useful in this case because the family had a limited income and limited availability to developmentally appropriate toys. Because the mother valued the child's learning to recognize the Disney characters, the therapist suggested the Disney Poppin' Pals toy from the toy library. This toy addressed the child's needs and interests (hand skills, communication, interaction) and the parents' values, and thus was a successful match.

Parent discussion group. A parent discussion group on play was also used to facilitate the parents' skills, knowledge, and understanding of the developmental stages of play and its importance to the social, cognitive, physical, and emotional development of their child. These discussions were designed to enhance the parents' ability to become facilitators and participants in play. Discussion group activities may include the following:

- Didactic information regarding play development given by the therapist.

- Articles regarding the importance of commonly played games (e.g., Medvescek, 1987). 
- Discussion of play activities currently observed by the parent to sharpen parents' skills in observing play.

- Feedback to parents about activities they describe doing at home.

The group was particularly useful for the mother in this case example, because it increased her knowledge of the importance of play for the acquisition of developmental skills. The information on the process of choosing toys and creating and organizing play environments assisted her in organizing the home play environment with developmentally appropriate toys.

\section{Pilot Data for the Effectiveness of the Family- Centered Framework for Early Intervention}

To generate data aimed at examining the effectiveness of the family-centered framework in an early intervention setting, we conducted a pilot study. For this study, the effectiveness of occupational therapy treatment was measured through observation of play behavior. The child's enhanced competence in interactions with the environment during play served as the indicator of success (Reilly, 1974; White, 1959). Play was chosen as a primary measure of competence because it is a major indicator of productive occupational behavior of childhood (Neville et al., 1985) and is a major arena for the development of competence in interaction with the environment (Ayres, 1972; Reilly, 1974). Because, within the framework, play is depicted as an activity that reflects and facilitates the development of the child, we anticipated that changes in play behavior would reflect developmental progress and indicate enhanced competence in interaction with the environment.

Five single-subject case studies, with a modified $A B$ design, were used to examine the effectiveness of the family-centered framework. The research question was, To what extent does competence in interaction with the environment (defined as play) improve when disabled toddlers and their families receive occupational therapy with the family-centered framework as part of their early intervention program? The subquestions were, (a) What are the changes in the play behaviors? (b) Are there changes in gross and fine motor developmental levels after the intervention period? and (c) What are the relationships between the changes in motor development and the changes in play behaviors?

\section{Method}

Subjects. Five preschoolers who were enrolled in the early intervention program in New Castle County, Delaware, participated in the study. Subject 1 (age 34 months) was diagnosed with failure to thrive syn- drome. Subject 2 (age 37 months) had hydrocephalus and was visually and hearing impaired. Subject 3 (age 36 months) was developmentally delayed. Subject 4 (age 32 months) had myotonic dystrophy and was developmentally delayed. Subject 5 (age 35 months) had congenital anomalies and was visually and hearing impaired. All of the subjects were scheduled to receive occupational therapy on the basis of previous evaluations.

Instrumentation. Three instruments were used to collect the data. The Preschool Play Scale (Bledsoe \& Shepherd, 1982; Knox, 1974) evaluates the play behavior of children from birth to 5 years of age in four dimensions: Space Management, Material Management, Imitation, and Participation. This scale yields a score for each dimension as well as an overall play age. The Parent/Teacher Play Questionnaire (Schaaf, Merrill, \& Kinsella, 1987) is a qualitative survey that obtains information from the parent, teacher, or both regarding the child's play choices, play times, and play behaviors for a given week. The Peabody Developmental Motor Scales (Folio \& Fewell, 1984), standardized for children from birth to 5 years of age, measures gross and fine motor skills. This test yields a gross and fine motor developmental age equivalent as well as a mean motor age equivalent (the average of the gross and fine motor age equivalents).

Procedure. Data were collected during a 4 -week baseline period and a 10 -week intervention period. It is important to note that these time periods were $\mathrm{lim}$ ited by the constraints of the early intervention program. That is, the baseline period was limited to a 4 -week period, after which treatment was required to begin.

Interrater reliability was established for the Preschool Play Scale through comparison of the scores for a subject rated by two of the three examiners during a free playtime session. This comparison was done four times. The interrater reliability scores for Investigators 1 and 2 were 1.0 and 0.972 , respectively; for Investigators 1 and 3, the scores were both 1.0. These high scores indicate that the three investigators were measuring the same behaviors and rating them in a reliable manner.

The Preschool Play Scale was administered twice during the baseline period and between four and five times during the intervention period. The test was administered in the subject's classroom during a free playtime period by the investigators (the authors of this study) and an occupational therapy student trained in its administration. The parents and the teacher were asked to complete the Parent/Teacher Play Questionnaire weekly during the 14-week study. The Peabody Developmental Motor Scales were ad. ministered before and after the intervention period. 


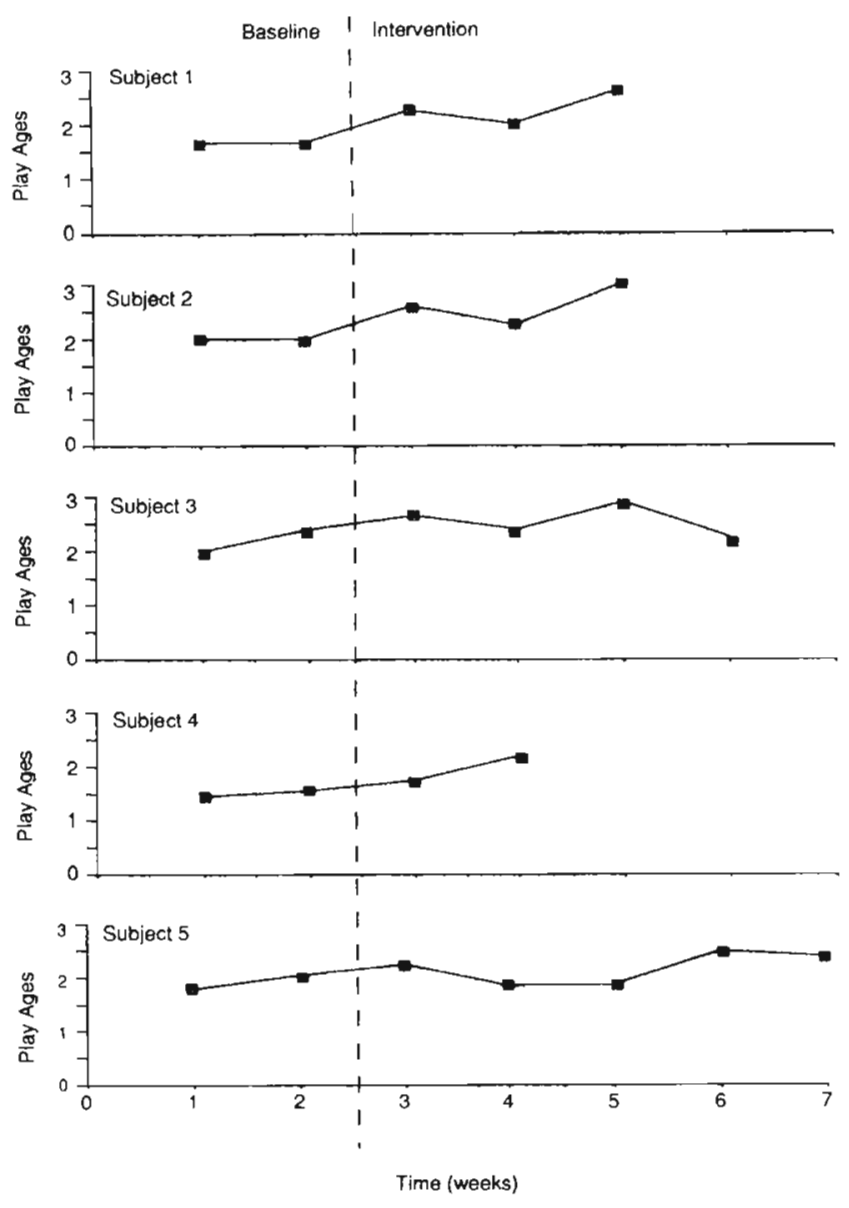

Figure 4. Subjects' play-age performances on the Preschool Play Scale (Bledsoe \& Shepherd, 1982; Knox, 1974) before and after intervention.

Intervention. Intervention consisted of direct and consultative occupational therapy in the home and early intervention environments. The intervention strategies were directed toward the parents, the classroom staff, and the 5 subjects. These strategies consisted of 1 -hour weekly home visits, in which environmental adaptations were made to facilitate play; a weekly parent discussion group to discuss the importance and relevance of play; and the use of a toy $\mathrm{li}$ brary. In addition, written classroom programs suggesting play activities to enhance deficit areas in individual children were given to the classroom staff. An effort was made to facilitate and expand the staff's awareness of play and its use both as an evaluative tool through observation and as an intervention modality. This was done through the sharing of articles on play development and through discussions at staff meetings

Data analysis. The play-age scores and dimension scores on the Preschool Play Scale for each child were visually examined (Ottenbacher, 1986) for changes occurring between the baseline and intervention phases. The Parent/Teacher Play Questionnaires were qualitatively analyzed for trends in play behavior and to determine if the trends supported the visual examination of the Preschool Play Scale data. The pre- and posttest scores on the Peabody Developmental Motor Scales were visually compared for differences in motor skills from pretesting to posttesting.

\section{Results}

Figure 4 shows the subjects' Preschool Play Scale play-age scores from baseline to intervention phases. Subjects 1 and 2 demonstrated a stable baseline and an overall increase in play age during the intervention phases. Subjects 3 and 5, whose intervention was initiated during an accelerated baseline phase, demonstrated inconsistent performance during the intervention phase. Subject 4 also had an accelerated baseline phase; the intervention phase, however, demonstrated an observable increase in play age.

Figures 5 through 8 show the Preschool Play Scale dimension scores for each subject. The dimen sion of Space Management (see Figure 5) demonstrates no observable changes. The dimension of Material Management (see Figure 6) shows an observable increase in Subjects 2 and 4, a slight increase in Subject 5, and inconsistent results in Subjects 1 and 3. The Imitation dimension (see Figure 7) does not demonstrate any striking changes. In the Participation dimension (see Figure 8), Subjects 1, 2, 3, and 4 demonstrated observable increases. Their baseline scores were fairly stable, whereas their intervention scores increased.

A qualitative analysis of the Parent/Teacher Play Questionnaires was difficult because of a poor response rate. Only 2 subjects had five or more questionnaires returned during the 14-week study. An analysis of these questionnaires indicated a trend toward the use of more manipulative toys, a longer attention span during play times, and an increase in verbalizations and language during play.

The Peabody Developmental Motor Scales preand posttest scores, shown in Table 1, do not demonstrate striking changes; however, the fine motor section showed more consistent increases in all subjects than did the gross motor scores.

\section{Discussion}

Interpretation of the study results must be qualified by the limitations of this study. This clinical research was conducted within an existing early intervention program and therefore was influenced by the daily procedures and idiosyncrasies of the program. Because the collection baseline and intervention data 

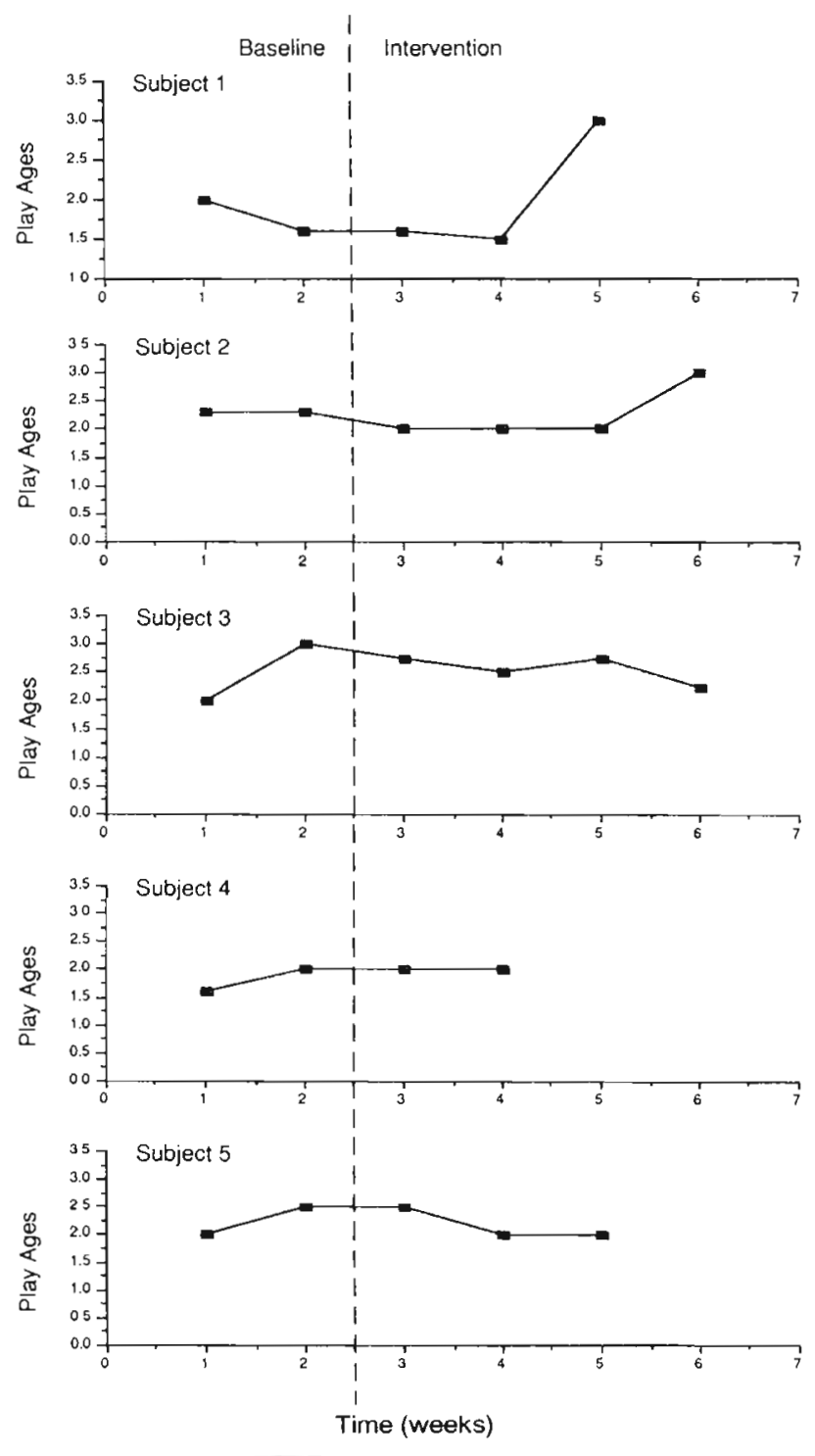

Figure 5. Subjects' performances on the Space Management dimension of the Preschool Play Scale (Bledsoe \& Shepherd, 1982; Knox, 1974) before and after intervention.

were limited by the time constraints of the early intervention program, it was impossible to follow a classic AB research design. A stable baseline was not achieved in several instances, which resulted in the intervention being initiated during an accelerated baseline phase. Thus, it is difficult to conclude whether the gains were due to the intervention. In addition, the collection of data was limited by the subjects' attendance in the program. Because of the subjects' frequent illnesses and absences, a less than desirable number of data points were collected during the baseline and intervention phases. The limited data points made it infeasible to conduct a visual analysis through the calculation and drawing of a celera- tion line (Ottenbacher, 1986). Because of these limitations, these data are presented and discussed as pilot data only.

Despite these limitations, the scattered positive changes lend initial support to the theoretical underpinnings of the family-centered framework, which state that an integrated, family-oriented model for occupational therapists working in early intervention will enhance the child's ability to interact compe tently in his or her environment. The use of play behavior as a measure of competence in young children and the use of this framework in enhancing their competence warrants further exploration, particularly with studies that use a classic $\mathrm{AB}$ single-subject design, a larger subject pool, or a control group.

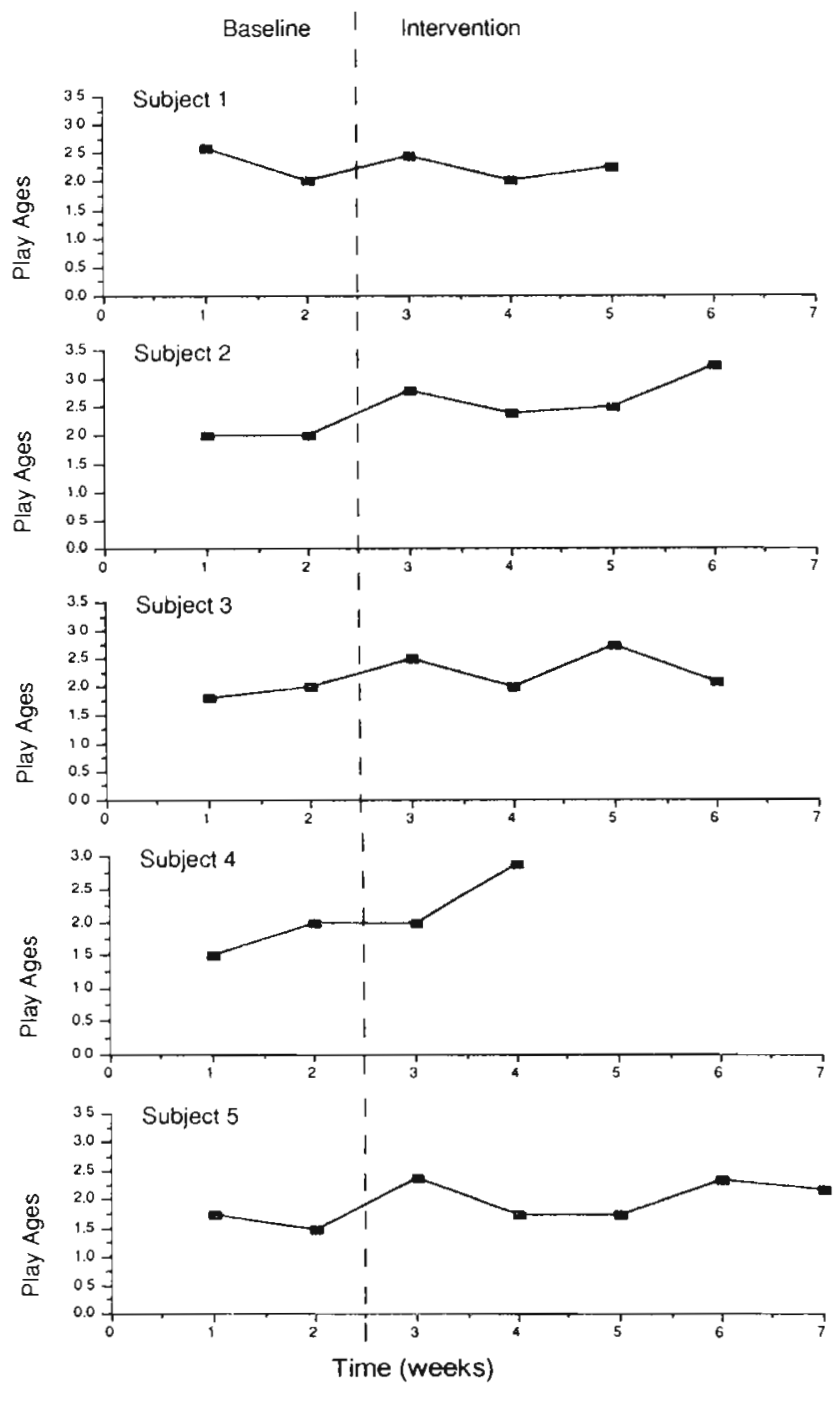

Figure 6. Subjects' performances on the Material Management dimension of the Preschool Play Scale (Bledsoe \& Shepherd, 1982; Knox, 1974) before and after intervention. 


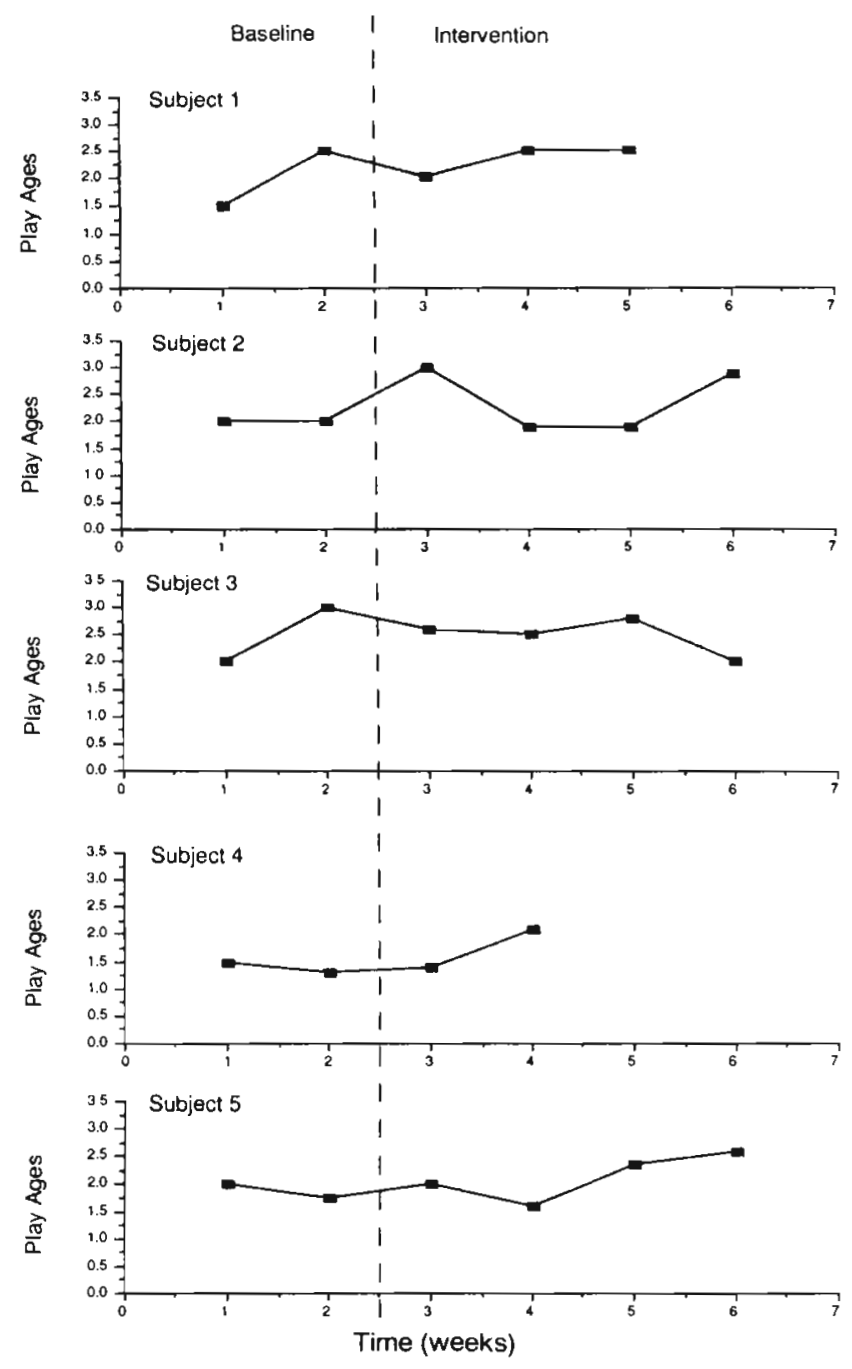

Figure 7. Subjects' performances on the Imitation dimension of the Preschool Play Scale (Bledsoe \& Shepherd, 1982; Knox, 1974) before and after intervention.

Of the four Preschool Play Scale dimension scores, we found it interesting that the Participation dimension demonstrated the most observable increases. Perhaps the children became more competent players and explorers, which allowed them to interact with others more consistently and at a higher developmental level. These changes in play behavior may also be relared to the parents and other family members taking a more active role in the play arena at home. Further exploration into the potential relationship of the family-centered framework on socialization skilis, such as those measured in the Participation dimension, is needed.

The Material Management dimension demonstrated observable increases in 2 , and possibly 3 , subjects. These children were manipulating objects with more purpose and at higher developmental levels, perhaps due to the change in toy choices and toy exposure in the home facilitated by occupational therapist-parent interactions. We found it interesting that these subjects' fine motor developmental ages also improved. The relationship between improvement in fine motor skills and improvement in play behavior, specifically Material Management, is interesting and warrants further study.

The Space Management and Imitation dimensions demonstrated no observable changes. Regarding Space Management, the children did not seem to physically explore their environments more during play, as measured by the Preschool Play Scale. These findings may indicate that more direct handling and facilitation of motor control may be necessary to ob-

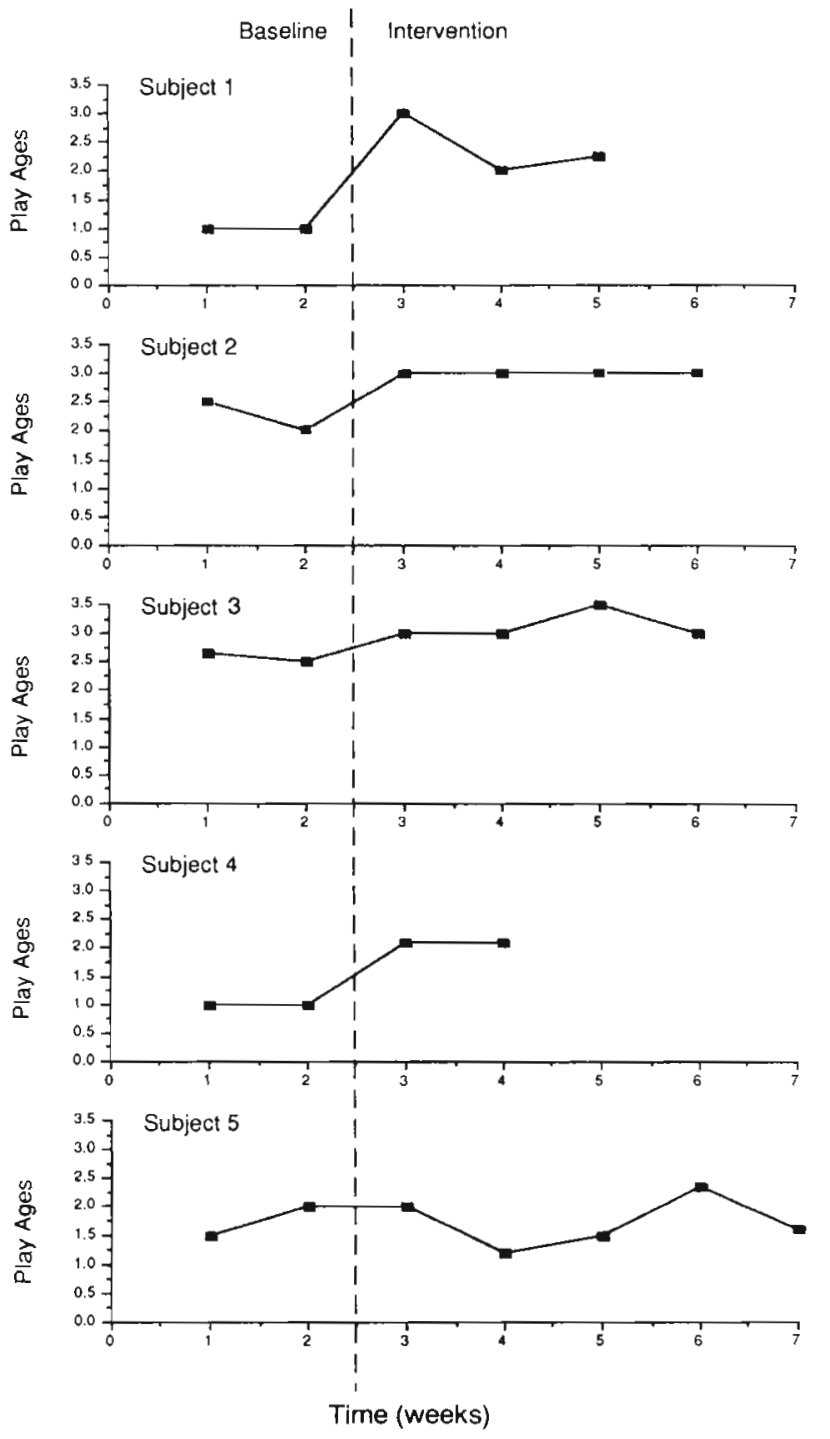

Figure 8. Subjects' performances on the Participation dimension of the Preschool Play Scale (Bledsoe \& Shepherd, 1982; Knox, 1974) before and after intervention. 
Table 1

Subjects' Pretest and Posttest Scores on the Peabody Developmental Motor Scales ${ }^{a}$

\begin{tabular}{|c|c|c|c|c|c|c|c|c|c|}
\hline \multirow[b]{2}{*}{ Subject } & \multicolumn{3}{|c|}{$\begin{array}{l}\text { Gross Motor Age Equivalent } \\
\text { (in months) }\end{array}$} & \multicolumn{3}{|c|}{$\begin{array}{l}\text { Fine Motor Age Equivalent } \\
\text { (in months) }\end{array}$} & \multicolumn{3}{|c|}{$\begin{array}{l}\text { Mean Motor Age Equivalent } \\
\text { (in months) }\end{array}$} \\
\hline & Pretest & Postlest & Change & Pretest & Posttest & Change & Pretest & Posulest & Change \\
\hline 1 & 21 & 24 & +3 & 26 & 28 & +2 & 23.5 & 26.0 & 2.5 \\
\hline 2 & 18 & 23 & +5 & 21 & 24 & +3 & 19.6 & 23.5 & 3.9 \\
\hline 4 & 14 & 16 & +2 & 14 & 19 & +5 & 14.0 & 17.5 & 3.5 \\
\hline 5 & 19 & 19 & - & 18 & 21 & +3 & 16.5 & 20.0 & 3.5 \\
\hline
\end{tabular}

Note. Subject 3 was not available for posttesting due to illness.

(Folio \& Fewell, 1984)

tain measurable gross motor skill changes in these children, as reflected in increased physical mobility during play.

Unfortunately, few of the Parent/Teacher Play Questionnaires were returned. A better response might have been facilitated through more frequent communication regarding the value of the information gained through the questionnaires. A condensed version of the questionnaire, which would require less time and effort for completion, may also be helpful. The obtainment of consistent information on the quality of play behaviors from these questionnaires would strengthen and lend validity to the study.

In addition to the limitations discussed above, there are two other concerns in interpreting these results. Because a stable baseline was not achieved or insufficient baseline data were collected, we cannot determine whether the changes in play behavior, as indicated by the Preschool Play Scale, were due to maturational factors or to the intervention. Additionally, the changes in play cannot be attributed exclusively to the intervention because the intervention was administered within the context of an interdisciplinary program. Of the four disciplines in this program, however, occupational therapy focused specifically on play behavior and family-centered intervention and actively explored and adapted the home and early intervention environments in relation to play behavior.

\section{Conclusion}

The results of this pilot study suggest that positive changes in play behavior can occur with use of the Family-Centered Framework for Early Intervention. Although these results must be interpreted cautiously in light of the limitations mentioned, they imply that occupational therapy, as part of an interdisciplinary early intervention program, may be effective in enhancing the child's competence in interacting with his or her environment. The use of play behavior as a measure of competence in the preschool population and the relationship of play behavior to motor skill development and socialization need further exploration.

\section{Acknowledgments}

We wish to thank Cathy Scutta for assistance with data collection; Elizabeth DePoy, Winnie Dunn, and Janice Burke for editorial assistance; Edward B. Dougherty for graphic assistance; and the program teacher, aide, parents, children, and other professionals who supported this study.

\section{References}

Ayres, A. J. (1972). Sensory integration and learning disorders. Los Angeles: Western Psychological Services. Ayres, A. J. (1979). Sensory integration and the cbild. Los Angeles: Western Psychological Services.

Bledsoe, N. P., \& Shepherd, J. T. (1982). A study of reliability and validity of a preschool play scale. American Journal of Occupational Therapy, 36, 783-788.

Chance, P. (1979). Learning through play. New York: Garner Press.

D'Eugenio, D. (1986). Infant play: A reflection of cognitive and motor development. In Play: A skill for life (pp. 55-66). Rockville, MD: American Occupational Therapy As. sociation.

Education of the Handicapped Act Amendments of 1986 (Public Law 99-457), 20 U.S.C. $\$ 1400$.

Florey, L. (1971). An approach to play and play development. American Journal of Occupationai Therapy, 25, 275-280.

Folio, R., \& Fewell, R. (1984). Peabody Developmental Motor Scales. Allen, TX: Developmental Learning Materials.

Kielhofner, G. (Ed.). (1985). A Model of Human OC. cupation: Theory and application. Balitmore: Williams \& Wilkins.

Kielhofner, G., \& Burke, J. P. (1980). A Model of Human Occupation, Part 1. Conceptual framework and content. American Journal of Occupational Therapy, 34, 572-581.

Kielhofner, G., Burke, J. P., \& Igi, C. H. (1980). A Model of Human Occupation, Part 4. Assessment and intervention. American Journal of Occupational Therapy, 34, $777-788$.

Knox, S. (1974). A play scale. In M. Reilly (Ed.), Play as exploratory learning (pp. 247-266). Beverly Hills, CA: Sage.

Lindquist, J. E., Mack, W. , \& Parham, L. D. (1982a). A synthesis of occupational behavior and sensory integration concepts in theory and practice, part 1. Theoretical founda- 
tions. American Journal of Occupational Therapy, 36, 365-374.

Lindquist, J. E., Mack, W., \& Parham, L. D. (1982b). A synthesis of occupational behavior and sensory integration concepts in theory and practice, part 2. Clinical applications. American Journal of Occupational Therapy, 36, 433-437.

Medvescek, C. (1987, June). Eight silly little games (and why they're so important). Parents Magazine, pp. 35-37.

Munoz, J. P. (1986). The significance of fostering play development in handicapped children. In Play: A skill for life (pp. 1-12). Rockville, MD: American Occupational Therapy Association

Neville, P., Kielhofner, G., \& Brasic-Royeen, C. (1985). Childhood. In G. Kielhofner (Ed.), A Model of Human Occupation: Theory and application (pp. 82-98). Baltimore: Williams \& Wilkins.
Ottenbacher, K. (1986). Evaluating clinical change: Strategies for occupational and physical therapists. Baltimore: Williams \& Wilkins.

Reilly, M. (Ed.). (1974). Play as exploratory learning. Beverly Hills, CA: Sage.

Schaaf, R. C., Merrill, S. C., \& Kinsella, N. (1987). Sensory integration and play behavior: A case study of the effectiveness of occupational therapy using sensory integrative techniques. Occupational Therapy in Health Care, 4, $61-75$.

Takata, N. (1969). The play history. American Journal of Occupational Therapy, 23, 314-318.

Takata, N. (1974). Play as prescription. In M. Reilly (Ed.), Play as exploratory learning (pp. 209-246). Beverly Hills, CA: Sage.

White, R. (1959). Motivation reconsidered: The concept of competence. Psychology Review, 66, 297-333.

\section{An AOTA Continuing Education Study Tour $\Delta$ July 9 through 19, 1990}

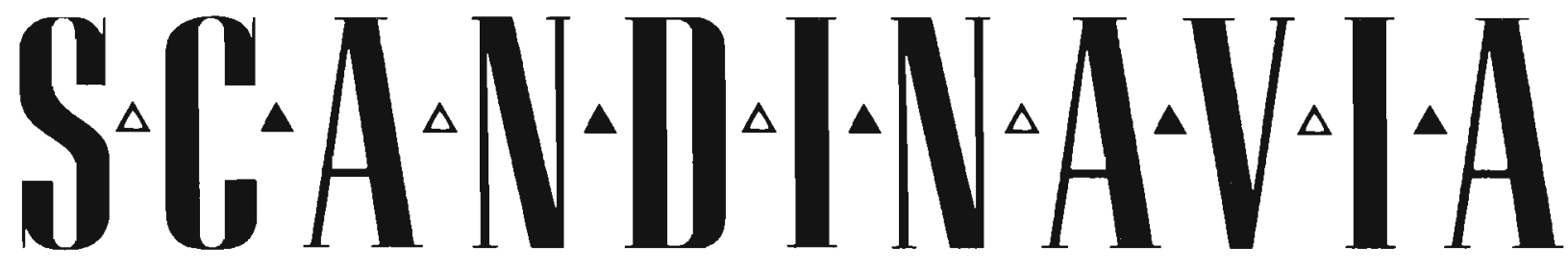

\section{Function and Independence: Scandinavian Approaches to Working with Adults}

For the first time AOTA is offering a study tour to Scandinavia. You can learn firsthand from Scandinavian occupational therapists as you travel through the beautiful countries of Denmark, Norway, and Sweden, during AOTA's continuing education tour.

This exclusive tour, designed especially for OTRs and COTAs, uses visits and discussions, plus presentations by experts from each country, to offer a comparative study of heatth care delivery systems from a Scandinavian perspective

Scandinavia. . known for its breathtaking beauty, diverse cultures, and rich heritage. . is also known for its high quality of occupational therapy. Strengthen your occupational therapy knowledge base, while experiencing Scandinavia.

Call Betty Cox at (307) 2435943 or send the coupon to receive more information.

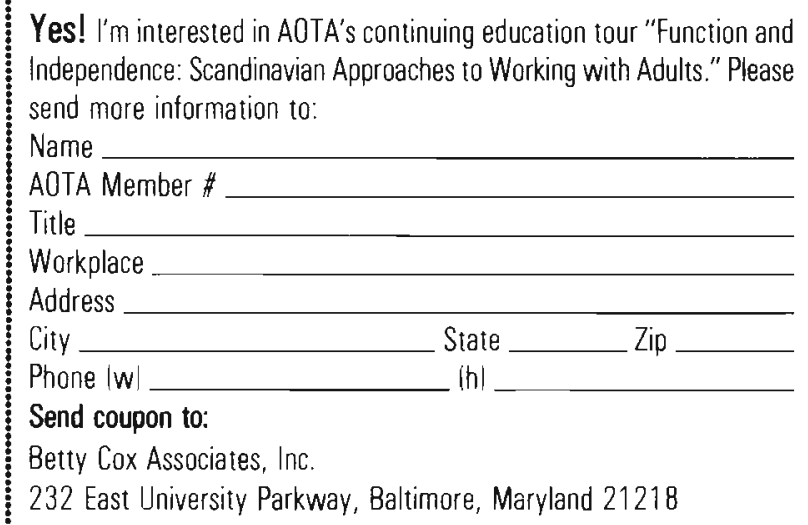

Yes! I'm interested in AOTA's continuing education tour "Function and Independence: Scandinavian Approaches to Working with Adults." Please send more information to:

Name

AOTA Member \#

Title

Workplace

Address

City

Phone $|w|$ (h) Zip

Send coupon to:

Betty Cox Associates, Inc

232 East University Parkway, Baltimore, Maryland 21218 